\title{
Pore, abnormal formation and fracture pressure prediction
}

\author{
F. Khoshnaw, P. Jaf \& S. Farkha \\ Petroleum Engineering Department, Koya University, Iraq
}

\begin{abstract}
Oil and gas well drilling planning is the main task of any drilling engineer. In order to overcome this task, it is required to maintain the wellbore pressure between the maximum value that does not fracture the formation and the pressure of the fluids within the formations, because, as the wellbore pressure exceeds the fractures' pressure, formation damage occurs, which will consequently result in lost circulation problems. Meanwhile, if the well pressure is less than the formation fluids pressure it leads to other drilling problems such as the kick problem and possibly blowout. The maximum well pressure that does not fracture the formations is called the fracture pressure and the formation fluids pressure is called the pore pressure. Therefore, pore pressure and fracture pressure are considered as the most crucial parameters for drilling engineering planning and for launching new wells. Another significant parameter for well planning is the detection and estimation of an abnormal pressure depth. This is when the formation pressure is higher than the normal pressure at a specific depth.

There are many methods for determining pore pressure, fracture pressure and abnormal pressure depth and their values. These methods can be divided into two categories: predictive methods and verification methods.

In this paper, the predictive method involves determining or estimating the above-mentioned parameters prior to drilling operation using seismic data, especially equivalent to matrix stress. This is applied to two case studies: an African sandstone reservoir in Libya and the South Texas Frio Trend, based on seismic data recorded for interval transit times vs. depth. The results showed that; first, for the African sandstone reservoir, Libya, the oil filed the abnormal pore pressure located deeper than $6000 \mathrm{ft}$, which is the main indicator for specifying that the maximum depth has an abnormal pressure. Second, for the South Texas Frio
\end{abstract}


Trend, the abnormal pore pressure was located at deeper than $8000 \mathrm{ft}$. In the last section, based on the pore and fractured gradient, the casing sets are selected. Keywords: pore pressure, abnormal pressure, fracture pressure, pore and fracture pressure gradient, prediction.

\section{Introduction}

\subsection{Concept of pressure}

Pressure is the ratio of force to the specific surface area over which a load is pressed. For instance, solids exert pressure; the most interesting examples of pressure in this paper involve fluid pressure, which may be gases and/or liquids, and/or water and air in particular cases within the subsurface of the earth. Pressure plays significant roles within the petroleum industry, among these is its function in the operation of lifting fluids from the subsurface while in upstream operations. The maintenance of ordinary formation pressure is essential to oil and gas production; the oil fields are perfectly suited to the ordinary pressure of the reservoir pressure, and that pressure is altered significantly and periodically throughout the time of production [1].

Within the oil and gas reservoirs there are some explicit pressure terms which should be analysed and then applied to a real case study from Sirt, Libya. Those terms are: pore pressure or formation pressure. They are defined as the pressure pressing on the fluids inside the pore space of a formation. For more clarification, overpressure or geopressures or abnormal pressures are defined as any pressures encountered which are greater than the normal fluid pressure. In addition to their definition, mathematical correlations are derived to encounter their value, for example, hydrostatic pressure, $\mathrm{P}_{\text {hyd }}$, is the pressure caused by the weight of a column of fluid:

$$
P_{h}=\rho_{f} g z
$$

where $z, \rho_{f}$ and $\mathrm{g}$ are the height of the column, the fluid density, and acceleration due to gravity, respectively [2].

\subsection{Borehole environment}

The situation of boreholes and the down status of oil and gas wells should be considered before launching any drilling operation. Thus, while planning and designing a well to be drilled it is crucial to consider the hydrostatic pressure of the drilling fluid, because if the pressure of the mud column above the pore zones is less than the pore pressure, the well is considered underbalanced. Eventually, sections of this well can collapse inside the wellbore, formation fluid can flow into the well from the surrounding rock and an uncontrolled flow of oil and gas into well is called a kick. In the extreme case, if the kick is not considered or dealt with, then that kick can lead to a blowout. As a result of the kick, the rock particles will fracture and break inside the well. 
On the other hand, if the hydrostatic pressure of the mud column is higher than the formation pressure, the well is considered as overbalanced. In unconsolidated formations, i.e. when the formation layers are carbonate rocks such as limestone and sandstone as shown in figure 1, this will force drilling mud to penetrate into the formation, thus causing mud filtrate within the zone of interest. Results from the overbalanced method are shown in figure 1, through which a damaged zone will be created and the degree of severity of the mud filtrate is illustrated in the same figure as follows [3]:

A. Invaded zone, the formation fluid is completely displaced by the mud filtrate;

B. Transition zone, the formation fluid is partially displaced by the mud filtrate;

C. Uninvaded zone is the zone which is not affected by the drilling fluid and also is called virgin zone.
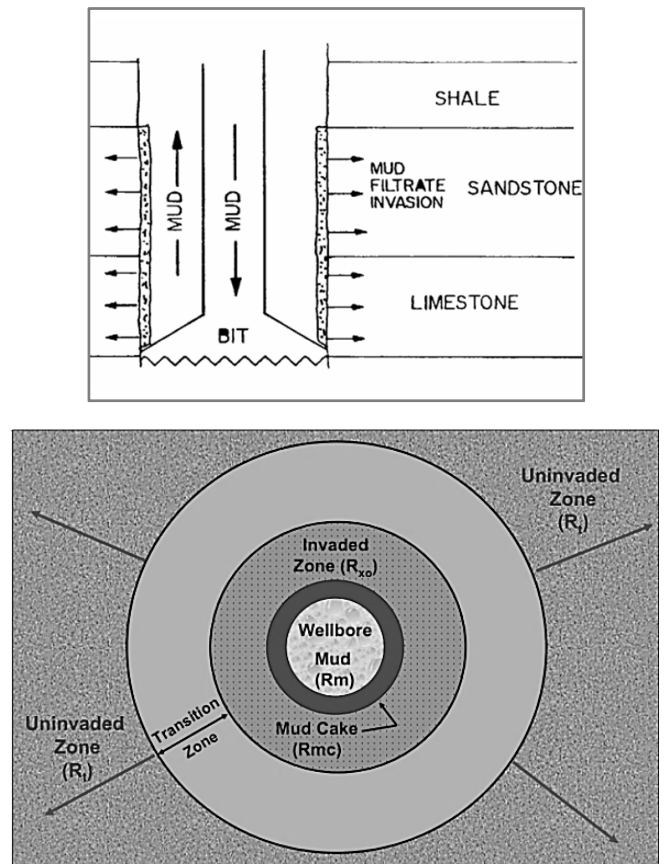

Figure 1: Borehole environment during drilling [3].

\section{Literature review}

\subsection{Fracture pressure concept}

Fracture pressure is the pressure in the wellbore at which a formation will crack. Fracture pressure may decrease with decreasing reservoir pressure. Hereby, it is habitually necessary to carry out "breakdown" tests to conclude the fracture pressure of a specific zone of an oil or gas reservoir. Figure 2 illustrates pressure behavior during a test to determine fracture pressure. 


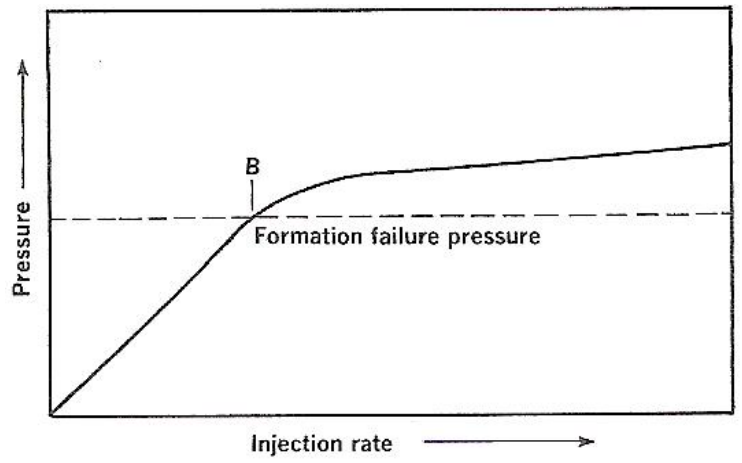

Figure 2: $\quad$ Test to determine fracture pressure [1].

The test procedure is to start pumping water or clean oil into the formation at a very slow rate, perhaps $1 / 4$ to $1 / 2$ bbl per minute for short zones, and measure the pump pressure. Then, increase the pump rate by steps and record the injection pressure until the injection rate-pressure curve breaks, as indicated in point B of figure 2. The stress within a rock can be resolved into three principal stresses. A formation will fracture when the pressure in the borehole exceeds the least of the stresses within the rock structure. Normally, these fractures will propagate in a direction perpendicular to the least principal stress [4].

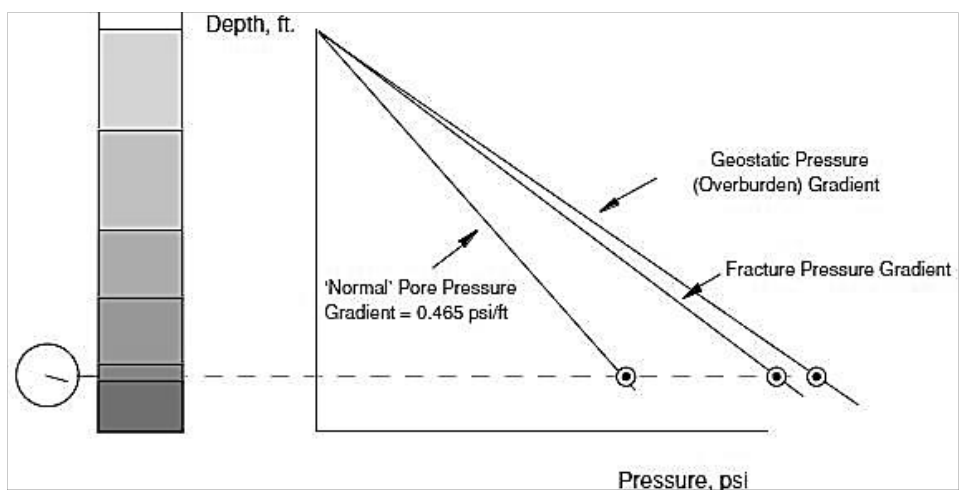

Figure 3: Pressure versus depth correlation [4].

\subsection{Matthew and Kelley correlation for fracture pressure prediction}

Matthews and Kelley replaced the assumption that the minimum stress was onethird the matrix stress by:

$$
\sigma_{\min }=F_{\sigma} \sigma_{m a}
$$

where the stress coefficient was determined empirically from field data that is taken from normally pressured formations. 
The vertical matrix stress at normal pressure is calculated (subscript " $n$ " is for normal pressure):

$$
\left(\mathrm{s}_{\mathrm{ma}}\right)_{\mathrm{n}}=\mathrm{s}_{\mathrm{obn}}-\mathrm{P}_{\mathrm{fn}}
$$

For simplicity, Matthews and Kelley assumed that the average overburden stress is $1 \mathrm{psi} / \mathrm{ft}$ and an average normal pressure gradient is $0.465 \mathrm{psi} / \mathrm{ft}$. To calculate abnormal fracture pressure, they introduced the depth $\mathrm{Di}$. Di is the equivalent normal pressure depth, which represents the abnormally pressured formation of interest depth.

$$
\left(\sigma_{m a}\right)_{n}=1 \times D_{i}-0.465 D_{i}=0.535 D_{i}
$$

At the depth at which the abnormal pressure presents:

$$
D_{i}=\frac{\left(\sigma_{m a}\right)_{n}}{0.535}=\frac{\sigma_{o b}-P_{f}}{0.535}=\frac{D-P_{f}}{0.535}
$$

\subsection{Abnormal pressure}

Abnormal pressure is diagnosed for a subsurface condition in which the pore pressure of a geologic formation exceeds or is less than the expected, or normal, formation pressure. When an impermeable layer of rocks such as shales are compacted quickly, fluids within their pores cannot continuously escape and thus will be added to the total overlying rock column, resulting in abnormally high formation pressures. Eventually, excess pressure, called overpressure, can cause a well to blowout or become uncontrollable during drilling. Severe under-pressure can cause the drilling strings to stick to the under-pressured formation.

\subsection{Pore pressure}

Pore pressure, or the pressure of fluids within the pores of a formation, is an important assessment that must be carefully made when planning a drilling project. Formations with pressures higher than hydrostatic pressures can be encountered in varying areas and depths. Being unaware of areas with overpressures can create many potentially catastrophic events such as blown reservoir seals, drilling fluid losses, or formation fluid influxes. There are many causes of overpressure; thus, it is vital to take the time to strategically plan, analyse, and model pore pressures and fracture pressures as accurately as possible.

\subsection{Importance of pore pressure calculations}

Two of the most important parameters in designing and drilling a well for oil and gas are the wells' pore pressure gradients and fracture gradients. This paper will show how pore pressure and fracture gradients change as a well is drilled deeper into the earth and how drilling engineers use drilling mud to manage the subsurface pressure. Pore pressure is the pressure which is exerted by fluids within the pore spaces of rocks. That pressure is generated by the rock in the fluids above the pore 
zones. When drillers encounter the zone of pores, which is hydrocarbon bearing rock, the pore pressure will force oil and gas out of the rock into the well, unless the drillers do something to counteract that pressure.

Drillers use drilling fluids, including drilling mud to counterbalance the pore pressure, through adjusting the column of the mud weight inside the well so that a pressure will be generated to the bottom of the well that equals to the pore pressure within the rocks. Consequently, the well will be kept in balance. Drillers measure the pore pressure in terms of the density of the mud column that would be required to balance that pressure. A plot of that pressure as shown in figure 4 can be expressed in terms of pressure units as a function of depth is called the pore pressure gradient [2].

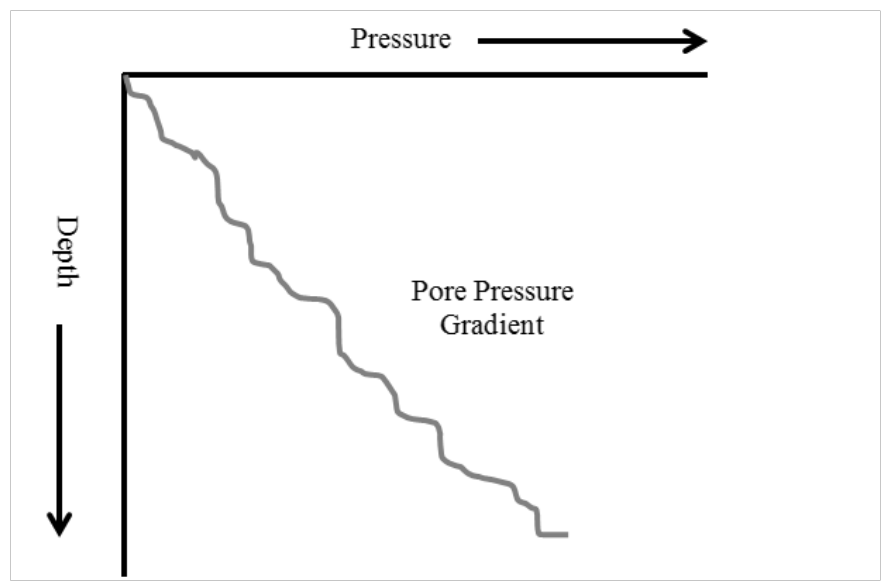

Figure 4: Pore pressure gradient [2].

\subsection{Estimation of formation pressures}

Hottman and Johnson developed a technique based on empirical relationships whereby an estimate of formation pressures could be made by noting the ratio between the observed and ordinary rock resistivities. As it is explained in their study, the following steps are required to evaluate the formation pressure:

1. The normal trend is established by plotting the logarithm of shale resistivity vs. depth.

2. The top of the pressured interval is found by noting the depth at which the plotted points diverge from the trend.

3. The pressure gradient at any depth is found as follows:

a) The ratio of the extrapolated normal shale resistivity to the observed shale resistivity is determined.

b) The formation pressure corresponding to the calculated ratio is determined using figure 5 . 


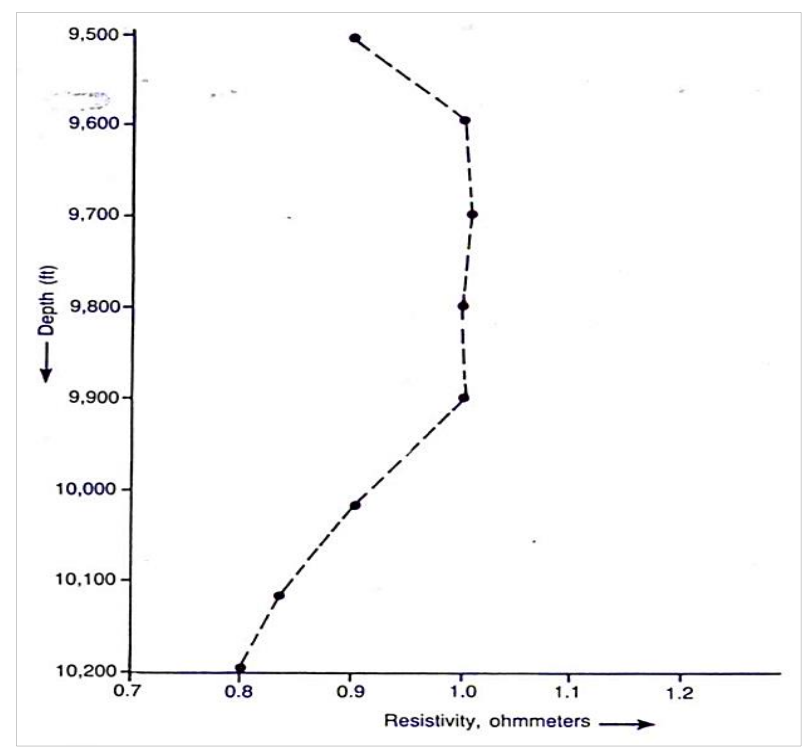

Figure 5: Shale resistivity from the $\log$ [4].

\subsection{Pore pressure prediction from seismic data}

Another method of estimating pore pressure is using seismic data collection. Through this method the advancement of seismic processing allows an increasingly accurate estimation of the velocities. This method allows the engineers and geoscientists to combine their knowledge and information to produce a valuable method for pore pressure prediction.

In short, the process of deriving accurate possible velocities from seismic processing is one of the key factors in predicting reliable pressure. As a result, this is where the role of the geophysicist comes into play in the process of pressure prediction. On the other hand, the geophysicist's information needs to be combined with an in-depth analysis of the well data, pressure data, and drilling data by an experienced person such as petrophysicist and drilling engineer. In addition to the engineering data and geophysicist's information, another important source of data to be gathered is from the role of the reservoir geophysicist for the integration of subsurface information with the specially conditioned seismic data to obtain reliable results [4].

\section{Methodology}

In the previous sections several methods, which are used to estimate and predict the pore pressure, have been described. In this section the equivalent matrix stress method will be used to predict the pore pressure and to find out both the pore pressure and the fracture pressure gradient. 


\subsection{Equivalent matrix stress}

This method can be applied by using seismic record data for Well Cat exploratory wells also for the sonic log data of the drilled section of the well, when the openhole logging tools are available. The procedure to estimate the pressure from the log-derived interval transit time vs. depth is the same and uses data either from a seismic record or a sonic log. The only difference is when shale formation is included in the analysis. The main difficulty in using seismic record data is lithology because it cannot be determined accurately; therefore, the average interval transit time for all formations must be present. However, it is often difficult to detect a sufficient number of shale points in the shallow pressured formation to establish a normal trend line with the data for a single well, as shown in figure 6.

Based on figure 6, the observed normal pressure trend line is drawn through the normal pressured zones, but at some point, the observed pressure is the same value as the above pressure point, which indicates an abnormal pressure formation; this is under the same matrix stress (grain-to-grain stress) [5]. For example, the matrix stress $\sigma_{\mathrm{g}}$ of an abnormally pressured formation at depth $\mathrm{D}$, which is the same matrix stress $\sigma_{\text {gn }}$ of a more shallow normally pressured formation at depth $\mathrm{D}_{\mathrm{n}}$, indicates the same porosity dependent parameter value $\Delta \mathrm{t}$.

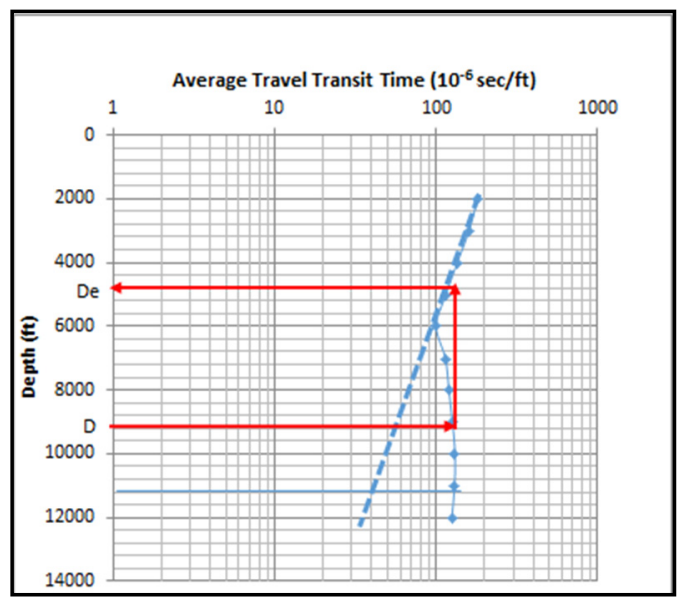

Figure 6: Porosity dependent parameter vs. depth [8].

At every depth point within the earth's subsurface, rocks are simulated by a piston being forced in equilibrium because of the balance of the forces acting upward and downward on these rocks. Based on the above expression; the overburden pressure is the relation between the matrix pressure and the formation pore pressure, as follows [6]:

$$
\sigma_{o b}=\sigma_{g}+P_{f}
$$


where:

$\sigma_{\mathrm{ob}}=$ total overburden pressure resulting from the geostatic load above, psi;

$\sigma \mathrm{g}=$ grain-to-grain pressure, $\mathrm{psi}$;

$\mathrm{P}_{\mathrm{f}}=$ fluid pressure inside the pores, $\mathrm{psi}$.

Therefore, for the matrix stress of abnormal and shallow pressured formations, the above equation can be written as the equivalent depth:

$$
\begin{aligned}
& \sigma_{o b(\mathrm{ab})}=\sigma_{g(\mathrm{ab})}+P_{f(\mathrm{ab})} \\
& \sigma_{o b(\mathrm{n})}=\sigma_{g(\mathrm{n})}+P_{f(\mathrm{n})}
\end{aligned}
$$

As previously mentioned, at both equivalent depths the matrix stresses are the same; therefore, the above equation can be written as:

$$
\sigma_{g(\mathrm{ab})}=\sigma_{g(n)}
$$

\subsubsection{Pore pressure gradient determination}

A relation between pore pressure and related depth can be expressed as:

$$
\text { pore pressure gradient }=\frac{\text { pore pressure }}{\text { depth }}
$$

Thus;

$$
G_{f}=\frac{p_{f}}{D}
$$

The pore pressure gradient can be solved simultaneously by the above two equations to give the following equation. The below equation is used to determine the formation pore pressure gradient at the selected depth $D$ :

$$
G_{f}=\frac{\left(G_{o b(a b)} \times D\right)+\left(G_{f(n)}-G_{o b(n)}\right) \times D_{e}}{D}
$$

where:

$\sigma_{\mathrm{ob}}(\mathrm{n})=$ The total overburden pressure, $\mathrm{psi}$;

$\sigma_{\mathrm{ob}}(\mathrm{ab})=$ The total overburden pressure, psi;

$\sigma_{\mathrm{g}}(\mathrm{n})=$ The normal grain to grain pressure, $\mathrm{psi}$;

$\sigma_{\mathrm{g}}(\mathrm{ab})=$ The abnormal grain to grain pressure, $\mathrm{psi}$;

$\mathrm{P}_{\mathrm{f}}(\mathrm{n})=$ The normal fluid pressure, $\mathrm{psi}$;

$\mathrm{P}_{\mathrm{f}}(\mathrm{ab})=$ The abnormal fluid pressure, $\mathrm{psi}$;

$\mathrm{G}_{\mathrm{ob}}(\mathrm{n})=$ The total overburden pressure gradient, psi;

$\mathrm{G}_{\mathrm{ob}}(\mathrm{ab})=$ The total overburden pressure gradient resulting from the abnormal geostatic load, psi;

$\mathrm{G}_{\mathrm{f}}(\mathrm{n})=$ The normal fluid pressure gradient, psi;

$\mathrm{G}_{\mathrm{f}}=$ The actual fluid pressure gradient, psi;

$\mathrm{D}_{\mathrm{e}}=$ Equivalent depth at the shallow formation, $\mathrm{ft}$;

$\mathrm{D}=$ Actual depth of interest, $\mathrm{ft}$. 
The overburden pressure gradient $\mathrm{G}_{\mathrm{ob}}$ can be obtained from the following equation:

$$
G_{o b}=0.433 \times \rho_{\mathrm{b}}
$$

where:

$\rho \mathrm{b}=$ Rock bulk density read from density log, gm/cc;

$0.433=$ Conversion factor from $\mathrm{gm} / \mathrm{cc}$ to $\mathrm{psi} / \mathrm{ft}$.

\subsubsection{Fracture pressure gradient determination}

Theoretically the fracture gradients can be determined if the geological conditions of the formation are known, including:

- Depth of the zone of interest;

- Formation fluid pressure within that zone;

- $\quad$ The rock type, i.e. sand, shale, etc.

There are some theoretical methods of determining the formation fluid pressure gradients and the formation fracture gradients such as Hubbert, Eaton, Mathews and Kelly.

As it has been described, the fracture pressure gradient should be known before drilling the wells in order to avoid fracturing of encountered formations and hence prevent lost circulation due to the wrong selection of mud weights. Consequently, the relation between the bottom hole pressure and the formation fracture gradient should be found in order to determine when and where a casing string set might be needed.

In this section, two correlations will be described to determine the fracture pressure gradient:

1. Hubbert and Willis (1957) suggested a correlation for the determination of the fracture gradient based on overburden pressure and formation pore pressure.

$$
\mathrm{FG}=\frac{1}{3}\left(\frac{\sigma_{\mathrm{ob}}}{\mathrm{D}}+\frac{2 \mathrm{P}_{\mathrm{f}}}{\mathrm{D}}\right)
$$

2. Eaton (1969) also proposed a correlation to give accurate results compared to the other methods and it is presented as follows:

$$
F G=\left(\frac{v}{1-v}\right)\left[\frac{\sigma_{o b}}{D}-\frac{P_{f}}{D}\right]+\frac{P_{f}}{D}
$$

where:

$\mathrm{FG}=$ Fracture pressure gradient, $\mathrm{psi} / \mathrm{ft}$;

$v=$ Poisson's ratio;

$\mathrm{P}_{\mathrm{f}}=$ Formation pore pressure, $\mathrm{psi}$;

$\sigma_{\mathrm{ob}}=$ Overburden pressure, psi.

The overburden pressure gradient is calculated using the density log readings as follows:

$$
\frac{\sigma_{\mathrm{ob}}}{\mathrm{D}}=0.433 \times \rho_{\mathrm{b}}
$$

where $\rho_{b}=$ Average rock bulk density read from density log. 


\section{Case studies}

\subsection{Case study A}

Seismic data was recorded from the African sandstone reservoir, Libya, as given in table 1 . The normal hydrostatic formation pore pressure obtained from the salinity data for the area is $0.449 \mathrm{psi} / \mathrm{ft}$. The average overburden pressure obtained from a density log in a nearby similar area is estimated to be $1.0 \mathrm{psi} / \mathrm{ft}$.

Table 1: Seismic data of African sandstone reservoir, Libya.

\begin{tabular}{|l|c|c|c|}
\hline $\begin{array}{l}\text { Average } \\
\text { depth } \mathrm{ft}\end{array}$ & $\begin{array}{c}\text { Average interval } \\
\text { transit time }\left(10^{-6} \mathrm{~s} / \mathrm{ft}\right)\end{array}$ & $\begin{array}{c}\text { Average } \\
\text { depth }\end{array}$ & $\begin{array}{c}\text { Average interval } \\
\text { transit time }\left(10^{-6} \mathrm{~s} / \mathrm{ft}\right)\end{array}$ \\
\hline 2000 & 180 & 8000 & 120 \\
\hline 3000 & 160 & 9000 & 126 \\
\hline 4000 & 135 & 10,000 & 131 \\
\hline 5000 & 115 & 11,000 & 130 \\
\hline 6000 & 100 & 12,000 & 130 \\
\hline 7000 & 114 & & \\
\hline
\end{tabular}

\subsection{Case study B}

Seismic data are recorded from the South Texas Frio Trend, as shown in table 2. The normal hydrostatic formation pore pressure obtained from the salinity data for the area is $0.450 \mathrm{psi} / \mathrm{ft}$. The average overburden pressure obtained from density $\log$ in a nearby similar area is estimated to be $1.0 \mathrm{psi} / \mathrm{ft}$ (Bourgoyne et al., 1991 [5]).

Table 2: Seismic data of the South Texas Frio Trend reservoir [5].

\begin{tabular}{|l|c|c|c|}
\hline $\begin{array}{l}\text { Average } \\
\text { depth } \mathrm{ft}\end{array}$ & $\begin{array}{c}\text { Average interval } \\
\text { transit time }\left(10^{-6} \mathrm{~s} / \mathrm{ft}\right)\end{array}$ & $\begin{array}{c}\text { Average } \\
\text { depth }\end{array}$ & $\begin{array}{c}\text { Average interval } \\
\text { transit time }\left(10^{-6} \mathrm{~s} / \mathrm{ft}\right)\end{array}$ \\
\hline 2000 & 137 & 8000 & 93 \\
\hline 3000 & 122 & 9000 & 115 \\
\hline 4000 & 107 & 10,000 & 132 \\
\hline 5000 & 104 & 11,000 & 130 \\
\hline 6000 & 98 & 12,000 & 126 \\
\hline 7000 & 95 & & \\
\hline
\end{tabular}




\section{Results and discussion}

For the first case study (African sandstone reservoir, Libya) after drawing the seismic transit travel time vs. depth in semi log papers (as shown in figure 7), the values in the table below are obtained from different selected depths at the abnormal pressure zone and their equivalent depths at the same interval transit times in the normal zone.

After determining the equivalent depth for each interval and determining the abnormal pressured formation depth, which is approximately lower than $6000 \mathrm{ft}$, the fracture pressured gradient with the pore pressure gradient are determined by using the Hubbert and Willis correlation method, as shown in table 3, and then the relations of pressure gradients are shown in figure 7 below, which shows the best way to determine the casing set within the well planning and acceptable mud weight.

Table 3: $\quad$ Pore pressure and fracture pressure gradients of African sandstone reservoir, Libya.

\begin{tabular}{|c|c|c|c|}
\hline $\begin{array}{c}\text { Actual depth } \\
\mathrm{ft}\end{array}$ & $\begin{array}{c}\text { Equivalent } \\
\text { depth } \mathrm{ft}\end{array}$ & $\begin{array}{c}\text { Pore pressure } \\
\text { gradient } \\
\text { (psi/ft) }\end{array}$ & $\begin{array}{c}\text { Fracture pressure } \\
\text { gradient }(\mathrm{psi} / \mathrm{ft})\end{array}$ \\
\hline 1000 & 1000 & 0.449 & 0.692 \\
\hline 2000 & 2000 & 0.449 & 0.691 \\
\hline 3000 & 3000 & 0.449 & 0.691 \\
\hline 4000 & 4000 & 0.449 & 0.691 \\
\hline 5000 & 5000 & 0.449 & 0.691 \\
\hline 6000 & 6000 & 0.449 & 0.691 \\
\hline 7000 & 5200 & 0.591 & 0.909 \\
\hline 8000 & 4800 & 0.669 & 1.031 \\
\hline 8500 & 4600 & 0.702 & 1.081 \\
\hline 8700 & 4700 & 0.702 & 1.081 \\
\hline 9000 & 4400 & 0.731 & 1.125 \\
\hline 9500 & 4300 & 0.751 & 1.156 \\
\hline 10,000 & 4200 & 0.769 & 1.183 \\
\hline 11,000 & 4200 & 0.790 & 1.216 \\
\hline 12,000 & 4700 & 0.784 & 1.207 \\
\hline & & & \\
\hline & & & 0 \\
\hline
\end{tabular}




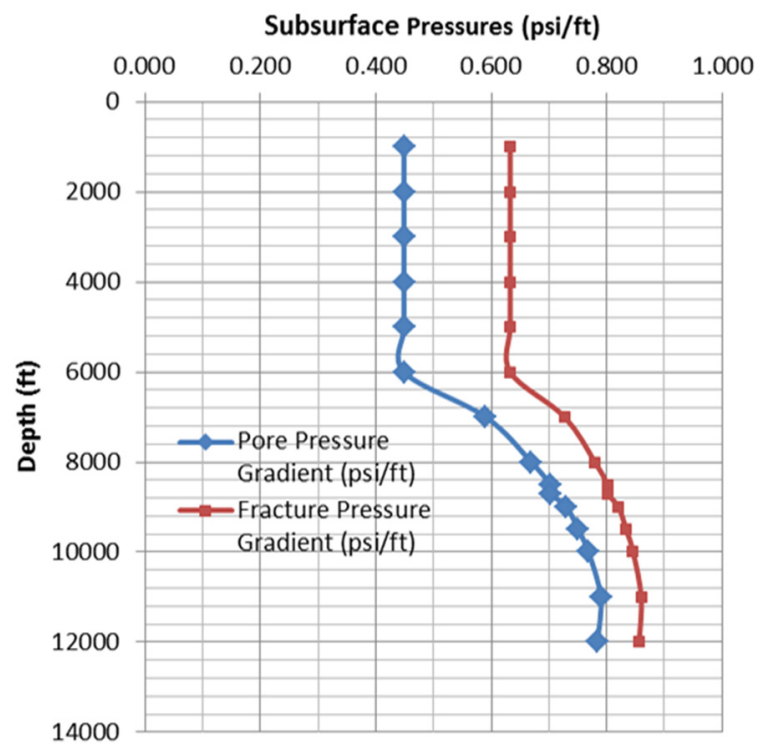

Figure 7: Subsurface formation pressures of African sandstone reservoir, Libya.

For the second case study (South Texas Frio Trend) the relation figure of the seismic transit travel time vs. depth in semi log paper shows that the values in the following table are obtained from different selected depths at the abnormal pressure zone and their equivalent depths at the same interval transit times. The abnormal zone is different from the first case study; therefore, it is clear to say that different pressure formations have a sufficient effect on the well planning (as shown in figure 8).

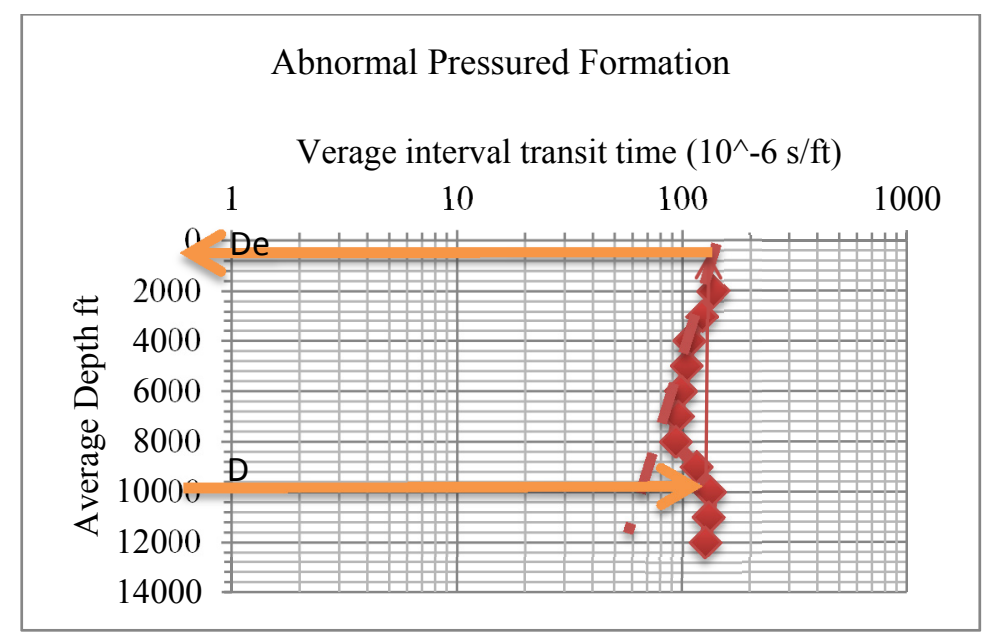

Figure 8: Abnormal pressure of South Texas Frio Trend reservoir [5]. 
After determining the equivalent depth for each interval and determining the abnormal pressured formation depth, which is roughly lower than $8000 \mathrm{ft}$, the fracture pressured gradient with pore pressure gradient are determined by using the Hubbert and Willis correlation method, as given in table 4. Finally, the relation of pressure gradients are shown in figure 9, which shows the best way to determine the casing set within the well planning and acceptable mud weight.

Table 4: $\quad$ Pore pressure and fracture pressure gradients of South Texas Frio Trend reservoir.

\begin{tabular}{|c|c|c|c|}
\hline $\begin{array}{c}\text { Actual } \\
\text { depth } \mathrm{ft}\end{array}$ & $\begin{array}{c}\text { Equivalent depth } \\
\mathrm{ft}\end{array}$ & $\begin{array}{c}\text { Pore pressure } \\
\text { Gradient }(\mathrm{psi} / \mathrm{ft})\end{array}$ & $\begin{array}{c}\text { Fracture pressure } \\
\text { gradient }(\mathrm{psi} / \mathrm{ft})\end{array}$ \\
\hline 2000 & 2000 & 0.550 & 0.847 \\
\hline 3000 & 3000 & 0.550 & 0.847 \\
\hline 4000 & 4000 & 0.550 & 0.847 \\
\hline 5000 & 5000 & 0.550 & 0.847 \\
\hline 6000 & 6000 & 0.550 & 0.847 \\
\hline 7000 & 7000 & 0.550 & 0.847 \\
\hline 8000 & 8000 & 0.550 & 0.847 \\
\hline 9000 & 3000 & 0.850 & 1.309 \\
\hline 10000 & 2250 & 0.899 & 1.384 \\
\hline 11000 & 2550 & 0.896 & 1.379 \\
\hline 12000 & 2600 & 0.903 & 1.390 \\
\hline
\end{tabular}

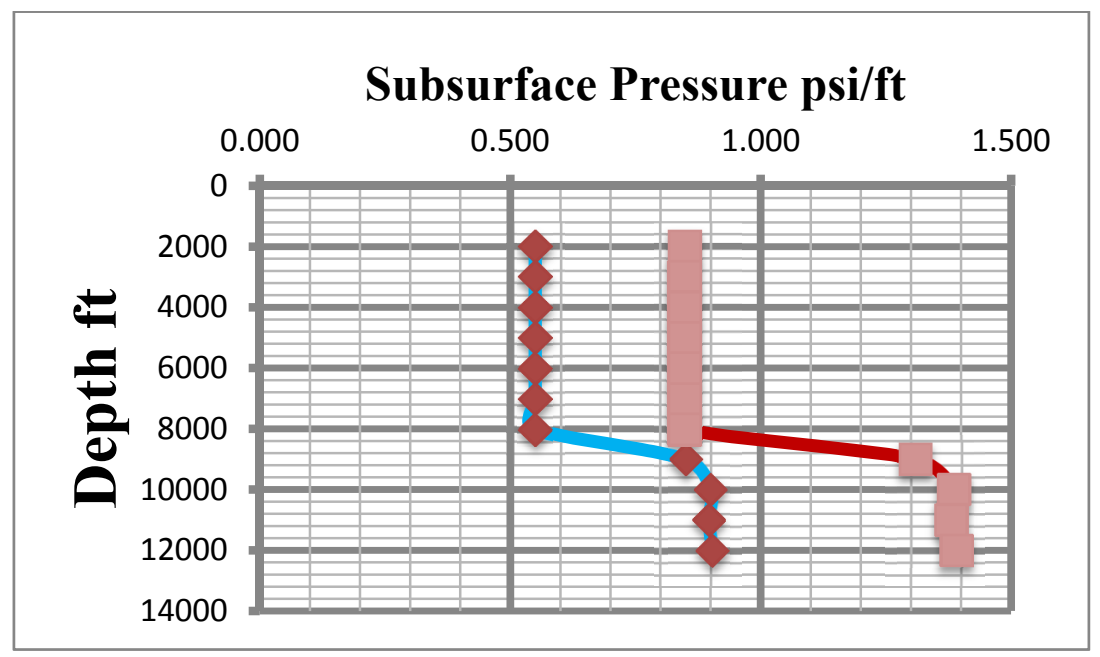

Figure 9: Subsurface formation pressures of South Texas Frio Trend reservoir [5]. 


\section{Conclusion}

In conclusion, there are a lot of direct and indirect perdition methods used to determine the pore and fracture pressure gradient. In a Well Cat drilling operation the only data available is seismic data; therefore, the equivalent matrix stress method is used for the two case studies.

- Based on the result of both case studies, there is different abnormal pressured formations, which is important to the drilling engineer in well planning.

- Pore and fracture pressure gradients are determined to analyse pressure distribution within the well bore, and pressure gradients vs. depth can be used to select the casing set and the acceptable mud weight.

\section{References}

[1] Daines, S.R.: Prediction of Fracture Pressures for Wildcat Wells, SPE 9254. SPE 55th Ann. Tech. Conference and Exhibition. Dallas, Tx, 21-24 Sept. 1980.

[2] Krynine, D.P. and Judd, W.R, (1957). Principles of Engineering Geology and Geotechnics, Chpt. 2, 46-79 McGraw-Hill.

[3] George Asquith and Daniel Krygowski (2004). Basic Well Log Analysis, (second edition), AAPG.

[4] Bikas Kumar, Sri Niwas and Bikram K. Mangaraj; Pore Pressure Prediction from Well Logs and Seismic Data. $9^{\text {th }}$ Biennial International Conference $\&$ Exposition on Petroleum Geophysics. HYDERABAD 2012, P005.

[5] Bourgoyne, J.R., Millheeim, K. K., Chenevert, M. E., et al., 1991, “Applied Drilling Engineering" Journal of Petroleum Science and Engineering, Textbook Series, Richardson, EUA.

[6] Halliburton Company (2000), Formation Pressure Evaluation Suite, Theory manual.

[7] Atashbari, V. Tingay, M.; Pore Pressure Prediction in Carbonate Reservoirs. SPE Journals 150835, 2012.

[8] Adam T. Bourgoyne Jr. et al., (1991). Applied Drilling Engineering. Society of petroleum engineers, Richardson, TX.

[9] Rev. B, (1996). Formation Pressure Evaluation. Baker Hughes INTEQ. Houston, TX 77073.

[10] José M. Carcione et al. Pore pressure estimation in reservoir rocks from seismic reflection data. Geophysics, Vol. 68, No. 5. pp. 1569-1579.

[11] Eaton, B.A. (1969). Fracture gradient prediction and interpretation of hydraulic fracture treatments. Journal of Petroleum Technology, October, 21-29.

[12] Fuyong Yan and De-hua Han; A new model for pore pressure prediction. University of Houston. SEG Las Vegas 2012 Annual Meeting, 2012.

[13] Hubbert, M. K. (1953). Entrapment of petroleum under hydrodynamic conditions, AAPG Bulletin. Vol. 37, pp. 1954-2026. 